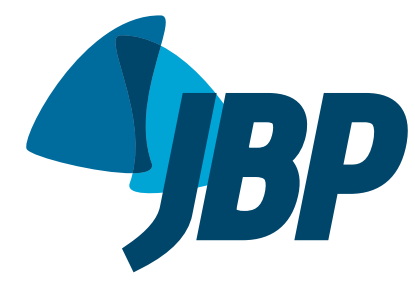

\title{
Electronic cigarette awareness and use among students at the Federal University of Mato Grosso, Brazil
}

\author{
Wemerson José Corrêa de Oliveira', ${ }^{1, a}$, Alexandre Figueiredo Zobiole ${ }^{1, b}$, \\ Claudia Bonadiman de Lima ${ }^{1, c}$, Rebeca Melo Zurita ${ }^{1, \mathrm{~d}}$, Pedro Eduardo Muniz Flores ${ }^{1, \mathrm{e}}$, \\ Luís Guilherme Val Rodrigues ${ }^{1, f}$, Raissa Carolina de Assis Pinheiro ${ }^{1, \mathrm{~g}}$, \\ Victor Francisco Figueiredo Rocha Soares e Silva ${ }^{1, h}$
}

1. Faculdade de Medicina, Universidade Federal de Mato Grosso, Cuiabá (MT) Brasil.

a. (ID) http://orcid.org/0000-0003-1945-1592

b. (iD http://orcid.org/0000-0002-9527-6055

c. (D) http://orcid.org/0000-0002-5935-516X

d. (D) http://orcid.org/0000-0002-5709-5202

e. (iD) http://orcid.org/0000-0003-2779-4675

f. (D) http://orcid.org/0000-0002-5503-9223

g. (D) http://orcid.org/0000-0003-3010-7610

h. (iD) http://orcid.org/0000-0002-3678-9475

Submitted: 30 June 2017.

Accepted: 7 December 2017

Study carried out at the Faculdade de

Medicina, Universidade Federal de Mato

Grosso, Cuiabá (MT) Brasil.

\begin{abstract}
Objective: To analyze the prevalence of electronic cigarette (e-cigarette) awareness and experimentation among university students, as well as the characteristics associated with that awareness. Methods: This was a cross-sectional study, conducted in 2015, in which 489 university students at the Federal University of Mato Grosso (Cuiabá campus), Brazil, were interviewed with the use of a specific questionnaire. We estimated the prevalence of e-cigarette awareness and use, as well as analyzing the major characteristics associated with that awareness and use. Results: The prevalence of e-cigarette awareness was $37 \%$, and the rate of e-cigarette experimentation was $2.7 \%$. Awareness of e-cigarettes was found to be associated with marital status, work status, the level of parental education, and the presence or absence of smokers in the family. Conclusions: A high proportion of university students were aware of e-cigarettes. Although the prevalence of those who had experimented with e-cigarettes was low, there is concern that there could be an increase in the use of these types of device. There is a need for measures targeting university students, in order to build awareness of and prevent e-cigarette use.
\end{abstract}

Keywords: Electronic Nicotine Delivery Systems; Young adult; Smoking.

\section{INTRODUCTION}

Invented in 2003, electronic cigarettes (e-cigarettes), also known as electronic nicotine delivery systems, are devices that produce an aerosol by heating a liquid that contains a solvent (vegetable glycerin, propylene glycol, or a mixture of these), flavorings, and nicotine. ${ }^{(1)}$ Some e-cigarettes have a light-emitting diode at the tip that is activated during use to simulate traditional smoking. (2)

The lack of regulation and quality control policies for e-cigarettes makes it difficult to determine the safety of these devices, and their potential health risks remain unclear. $^{(3)}$ In Brazil, according to Article 1 of Brazilian National Health Oversight Agency Collegiate Board Resolution no. 46/2009,(4) "it is forbidden to market, import, or advertise electronic smoking devices, known as electronic cigarettes, e-cigarettes, e-cigs, e-cigars, vaporizers, etc., especially those claiming to be a substitute for cigarettes, cigarillos, cigars, pipes, and similar products in the smoking habit or aimed at being an aid in smoking cessation treatment."

The use of e-cigarettes has increased exponentially since their invention in 2003. In 2010, $1.8 \%$ of U.S. adults reported having used an e-cigarette at some time, a rate that rose to $13 \%$ by 2013 . The rate of those who reported being current e-cigarette users increased from $0.3 \%$ to $6.8 \%$ during the same period, and one third of these reported never having used tobacco. ${ }^{(1)}$
To determine the profile of e-cigarette users in the United States., a study based on data from the U.S. National Center for Health Statistics, published in 2016 by the American Journal of Preventive Medicine, showed that, unlike traditional cigarette smokers (African-Americans and individuals with a low level of education), e-cigarette users tended to be young, White, and single, as well as having a college education level. ${ }^{(5)}$

Few studies in Brazil have examined e-cigarette awareness and use. A study on awareness, experimentation, and current use of e-cigarettes in 10 countries, which is a result of the International Tobacco Control Project and was published in 2014 in the International Journal of Environmental Research and Public Health, showed that, in Brazil, the prevalence of e-cigarette awareness was 35\% and the self-reported rate of e-cigarette experimentation was $3 \%$. Those are comparable to the values reported for Canada and China, but are lower than those found in the United States and Australia, where the prevalence of e-cigarette awareness was $73 \%$ and $66 \%$, respectively, and the self-reported rate of e-cigarette experimentation was $15 \%$ and $20 \%$, respectively. ${ }^{(6)}$

Recent studies have suggested that e-cigarette use might be associated with an increased risk of using tobacco products. Enjoyment of the sensations and pharmacological effects of inhaling nicotine via an e-cigarette may increase propensity to use other products

Correspondence to:

Wemerson José Corrêa de Oliveira. Faculdade de Medicina, Universidade Federal de Mato Grosso, Rua Nove, Quadra 09, Casa 12, Coophamil, CEP 78028-105, Cuiabá, MT, Brasil.

Tel.: 5565 98160-0178. E-mail: wemersonjco@hotmail.com

Financial support: None. 
that also deliver inhaled nicotine, including tobacco products. ${ }^{(7)}$ If e-cigarettes prove to be a means of "transition", leading to an increase in smoking, that will represent a serious public health problem in the fight against tobacco use. ${ }^{(8)}$

Since that e-cigarette awareness and experimentation have progressively increased, especially among young people, and considering the uncertainties regarding the safety and health risks of e-cigarettes, we designed this study. The objective of this study was to identify the prevalence of e-cigarette awareness and use, as well as to analyze the characteristics associated with that awareness, among students at the Federal University of Mato Grosso (Cuiabá campus), Brazil, in 2015. In addition, we aimed to lay the groundwork future public health initiatives focusing on measures to prevent and build awareness of e-cigarette use.

\section{METHODS}

This was an observational cross-sectional study involving undergraduate students at the Federal University of Mato Grosso (Cuiabá campus), Brazil, conducted in 2015.

The sample size was calculated on the basis of the prevalence of smoking among undergraduate health sciences students in the city of Cuiabá, Brazil, in $2009,{ }^{(9)}$ which was $9 \%$, and the sampling error was set at 0.05 . The random sampling was based on data from the 2012 Mandate of the Unified Selection System for the Federal University of Mato Grosso. The courses were grouped by area of knowledge (as defined by the Brazilian National Council for Scientific and Technological Development), ${ }^{(10)}$ and the sample size was calculated proportionally to the number of students in each area. The sample size was increased by $20 \%$ to account for losses and refusals. Data were collected with a standardized, pre-codified, multiplechoice self-administered, anonymous questionnaire that was developed by the authors based on the Special Smoking Survey questionnaire (2008 Brazil Report).(11) The questionnaire was previously tested for comprehension on students from a class at the Federal University of Mato Grosso, in order to correct possible problems and standardize the instrument. A total of 524 questionnaires were distributed. Of those, 35 were excluded from the analysis because of inconsistencies in their completion, such as missing data on sociodemographics and smoking status, and, therefore, there were 489 valid questionnaires.

Data analysis was performed using Epi Info, version 3.5.2. In the bivariate analysis, prevalence ratios and their corresponding $95 \%$ confidence intervals were used as a measure of association between the dependent variable (e-cigarette awareness) and the other variables studied. At this stage, the chi-square test was used in order to identify statistical differences between proportions.

The study project was approved by the Research Ethics Committee of the Júlio Muller University Hospital
(Ruling no. 1,443,745). In addition, permission for data collection was obtained from the Dean's Office of the Federal University of Mato Grosso (Cuiabá campus).

\section{RESULTS}

A total of 489 undergraduate students participated in the study. Of those, 258 (52.7\%) were male and $231(47.3 \%)$ were female, and the overall mean age was 23.8 years. Among the participants, 28 (5.7\%) were smokers, 24 (4.9\%) were former smokers, and 437 (89.4\%) were nonsmokers.

The prevalence of e-cigarette awareness was 37\%, and there was a statistically significant difference between genders, with 106 students (59\%) being male and $75(41 \%)$ being female $(p<0.005)$. There was an inversely proportional linear association between e-cigarette awareness and student age, that is, the younger the student, the greater the likelihood that he/she would be aware of e-cigarettes. No courserelated difference was noted in e-cigarette awareness. E-cigarette awareness was found to be significantly associated with marital status and work status, 163 students (92.1\%) being single and 130 (72.6\%) being unemployed $(p<0.005)$. In addition, e-cigarette awareness was associated with a higher level of parental education, given that, in 72 cases $(40.4 \%)$, the father had a college education level, and, in 86 $(47.8 \%)$, the mother did it. A positive association was also observed between e-cigarette awareness and the presence of smokers in the family $(55.6 \% ; p=0.03)$.

The rate of current e-cigarette use among the students was $0.61 \%$. In addition, the rate of e-cigarette experimentation among all respondents was $2.7 \%$, and, among those who reported being aware of e-cigarettes, that rate was $7 \%$.

\section{DISCUSSION}

The present study is one of the first to examine e-cigarette awareness among university students in Brazil. The results presented here may inform future interventions aimed at promoting healthy lifestyle habits among undergraduate students.

The prevalence of e-cigarette awareness found among university students in this study is higher than that reported by Jeon et al. ${ }^{(12)}$ in a study of university students in Korea in 2016 (21.2\%) and that found in the American population in 2010 (32.2\%). ${ }^{(13)}$ In addition, it is slightly higher than the national prevalence in Brazil $(35 \%))^{(6)}$ This may have occurred because of the spread of aggressive advertising campaigns by e-cigarette manufacturers aiming to promote e-cigarette use. The main arguments of the e-cigarette industry include the health benefits of e-cigarettes over traditional cigarettes, the reduction in the consumption of traditional cigarettes, the cessation of smoking, the minimization of passive exposure, and the possibility of using e-cigarettes in places where smoking is forbidden.

Another important piece of information that should be highlighted in this study is the fact that most of the students who were aware of e-cigarettes 
were nonsmokers. This datum is different from that reported by some authors, ${ }^{(13)}$ according to whom most of the adults who had heard of e-cigarettes were smokers (49.6\%). In addition, we found that the rate of e-cigarette awareness was highest among the youngest students. A study published in $2013^{(14)}$ also found a similar result among British adults: $41 \%$ of the individuals between 19-24 years of age had heard of e-cigarettes. These data can be explained by the fact that this public has greater access to information and is more exposed to e-cigarette industry advertising.

We found that the male gender was more strongly related to e-cigarette awareness, as was also observed in a study published in $2017^{(5)}$ Our study shows that the students who were aware of e-cigarettes were those whose parents had a higher level of education. Similar data were also reported by a study published in $2005,{ }^{(15)}$ in which $40 \%$ and $44.6 \%$ of fathers and mothers, respectively, had a college education level; however, the study focused on traditional smoking rather than e-cigarettes. In contrast, a study published in $2008^{(16)}$ showed an inverse relationship between the level of parental education and tobacco experimentation.

Although no statistically significant, course-related difference was noted, we found that the rate of e-cigarette experimentation was higher among undergraduates in the human, social, and agricultural sciences. This was also observed among students at the University of Brasília, Brazil, in 2006. (17) $^{(17}$

In the present study, there was a statistically significant association between e-cigarette experimentation and having smokers in the family. This was also observed among university students in Korea in 2016. ${ }^{(12)}$ We also found that not having a job was associated with greater e-cigarette awareness.

In our total sample, the rate of e-cigarette experimentation was found to be highest in the group of those who were aware of e-cigarettes (7\%), from which it can be inferred that awareness arouses curiosity and leads to experimentation. This percentage is lower than that found in a study published in 2013,(18) in which $16 \%$ of those who were aware of e-cigarettes had tried them.

The rate of regular e-cigarette use in this study was $0.61 \%$, a value that is close to that found among university students in Korea: $0.8 \%$ of the smokers used only e-cigarettes. ${ }^{(12)}$ A study published in $2013^{(14)}$ found a $6.9 \%$ rate of regular e-cigarette use among British adults; however, it should be considered that e-cigarette use and marketing are allowed and regulated in Great Britain, which explains the higher prevalence of regular users.

Therefore, considering the awareness and availability of e-cigarettes among university students and the general population, it is essential that there are interventions that have the objective of promoting healthy habits among the students and that can discourage the use of these types of device, ultimately preventing the increase in the consumption of other products that also release inhaled nicotine, including tobacco products.

\section{REFERENCES}

1. Dinakar C, O'Connor GT. The Health Effects of Electronic Cigarettes. N Engl J Med. 2016;375(14):1372-1381. https://doi.org/10.1056/ NEJMra1502466

2. Knorst MM, Benedetto IG, Hoffmeister MC, Gazzana MB. The electronic cigarette: the new cigarette of the 21st century? J Bras Pneumol. 2014;40(5):564-72. https://doi.org/10.1590/S180637132014000500013

3. Goniewicz ML, Knysak J, Gawron M, Kosmider L, Sobczak A, Kurek $J$, et al. Levels of selected carcinogens and toxicants in vapour from electronic cigarettes. Tob Control. 2014;23(2):133-9. https://doi. org/10.1136/tobaccocontrol-2012-050859

4. Brasil. Ministério da Saúde. Agência Nacional de Vigilância Sanitária [homepage on the Internet]. Brasília: o Ministério; [cited 2017 May 1]. Resolução da Diretoria Colegiada-RDC 46/2009 (Aug 28, 2009). [Adobe Acrobat document, 2p.]. Available from: http://portal. anvisa.gov.br/documents/10181/2718376/RDC_46_2009_COMP. pdf/2148a322-03ad-42c3-b5ba-718243bd1919

5. Wilson FA, Wang Y. Recent Findings on the Prevalence of E-Cigarette Use Among Adults in the U.S. Am J Prev Med. 2017;52(3):385-390. https://doi.org/10.1016/j.amepre.2016.10.029

6. Gravely S, Fong GT, Cummings KM, Yan M, Quah AC, Borland S, et al. Awareness, trial, and current use of electronic cigarettes in 10 countries: Findings from the ITC project. Int J Environ Res Public Health. 2014;11(11):11691-704. https://doi.org/10.3390/ ijerph111111691

7. Leventhal AM, Strong DR, Kirkpatrick MG, Unger JB, Sussman S, Riggs NR, et al. Association of Electronic Cigarette Use With Initiation of Combustible Tobacco Product Smoking in Early Adolescence. JAMA. 2015;314(7):700-7 https://doi.org/10.1001/jama.2015.8950

8. Fairchild $A L$, Bayer $R$, Colgrove. The renormalization of smoking? E-cigarettes and the tobacco "endgame". N Engl J Med. 2014;370(4):293-5. https://doi.org/10.1056/NEJMp1313940

9. Botelho C, Silva AM, Melo CD. Smoking among undergraduate health sciences students: prevalence and knowledge. J Bras Pneumol. 2011;37(3):360-6. https://doi.org/10.1590/S1806-

\section{3}

10. Conselho Nacional de Desenvolvimento Científico e Tecnológico (CNPq) [homepage on the Internet]. Brasilia: CNPq; [cited 2016 Dec 1]. Tabela de Áreas de Conhecimento 2008. [Adobe Acrobat document, 22p.]. Available from: http://www.cnpq.br/documents/10157/186158/ TabeladeAreasdoConhecimento.pdf

11. Brasil. Ministério da Saúde. Pesquisa Especial de Tabagismo (PETab) Relatório Brasil. Rio de Janeiro: Ministério da Saúde, Instituto Nacional de Câncer/Organização Pan-Americana da Saúde; 2011.

12. Jeon C, Jung KJ, Kimm H, Lee S, Barrington-Trimis JL, McConnell $R$, et al. E-cigarettes, conventional cigarettes, and dual use in Korean adolescents and university students: Prevalence and risk factors. Drug Alcohol Depend. 2016;168:99-103. https://doi.org/10.1016/j. drugalcdep.2016.08.636

13. Regan AK, Promoff G, Dube SR, Arrazola R. Electronic nicotine delivery systems: adult use and awareness of the 'e-cigarette' in the USA. Tob Control. 2013;22(1):19-23. https://doi.org/10.1136/ tobaccocontrol-2011-050044

14. Dockrell M, Morrison R, Bauld L, McNeill A. E-cigarettes: prevalence and attitudes in Great Britain. Nicotine Tob Res. 2013;15(10):1737-44. https://doi.org/10.1093/ntr/ntt057

15. Nascimento D, Soares EA, Feitosa S, Colares V. Tobacco smoking habit among adolescents in the city of Recife and associated factors [Article in Portuguese] Rev Odontol Ciência. 2005;20(4):348-53.

16. Silva MP, Silva RM, Botelho C. Factors associated with cigarette experimentationamong adolescents. J Bras Pneumol. 2008;34(11):92735. https://doi.org/10.1590/S1806-37132008001100007

17. Andrade AP, Bernardo AC, Viegas CA, Ferreira DB, Gomes TC, Sales MR. Prevalence and characteristics of smoking among youth attending the University of Brasilia in Brazil. J Bras Pneumol. 2006;32(1):23-8. https://doi.org/10.1590/S1806-37132006000100007

18. Adkison SE, O'Connor RJ, Bansal-Travers M, Hyland A, Borland R, Yong $\mathrm{HH}$, et al. Electronic nicotine delivery systems: international tobacco control four-country survey. Am J Prev Med. 2013;44(3):20715. https://doi.org/10.1016/j.amepre.2012.10.018 